To appear in Current Opinion in Psychiatry, May 2007

Addictive disorders

\title{
Alcohol Use among College Students: an International Perspective
}

Elie Karam ${ }^{\text {abc }}$

Kypros Kypri $^{\text {de }}$

Mariana Salamoun ${ }^{\mathrm{c}}$

${ }^{a}$ Department of Psychiatry and Clinical Psychology, St George Hospital University Medical Center, Lebanon

${ }^{\mathrm{b}}$ Department of Psychiatry and Clinical Psychology, Balamand University, Lebanon

${ }^{\mathrm{c}}$ Institute for Development Research Advocacy and Applied Care (IDRAAC), Lebanon

${ }^{\mathrm{d}}$ School of Medicine and Public Health, University of Newcastle, Australia

${ }^{\mathrm{e}}$ Injury Prevention Research Unit, University of Otago, New Zealand

Correspondence to Elie Karam, MD

Tel/Fax: +961 1583583

E-mail: egkaram@idraac.org / www.idraac.org 
To appear in Current Opinion in Psychiatry, May 2007

\section{Purpose of review}

This review of published articles in the period 2005-2006 on alcohol use among college students in Africa, Asia, Australasia, Europe and South America assesses the prevalence of alcohol use, hazardous drinking and related problems, and reviews the effectiveness of intervention methods, and implications for future research.

\section{Recent findings}

Research on alcohol use and related problems in college students is lacking in many regions of the world. We identified 26 papers in peer-reviewed journals, from Australia, Brazil, Ecuador, Egypt, Germany, Hong Kong, Ireland, Lebanon, New Zealand, Nigeria, Sweden, The Netherlands, and Turkey.

\section{Summary}

There is a need for more comprehensive studies with systematic methodologies in the world regions reviewed here to yield representative results on alcohol use and related risk and protective factors in college settings. On the basis of what has been published so far, college students in many countries are at an elevated risk for heavy drinking, with serious immediate health risks, such as drink-driving and other substance use; and longer term risks, such as alcohol dependence. The prevalence of hazardous drinking in Australasia, Europe and South America, appears similar to that in North America, but is lower in Africa and Asia. Alcohol policies should be reviewed and prevention programs initiated in light of research evidence, for this high risk population group.

\section{Keywords}

alcohol; college; university; students; substance 
To appear in Current Opinion in Psychiatry, May 2007

\section{Abbreviations}

AUDIT Alcohol Use Disorders Identification Test

BAC Blood Alcohol Concentration

RCT randomized controlled trial

SBI screening and brief intervention

e-SBI electronic screening and brief intervention

ICD-10 International Classification of Diseases-10

CIDI Composite International Diagnostic Interview

SRAS Self Rating Anxiety Scale

YRBS Youth Risk Behaviour Survey

NEADA Nurse Education in Alcohol and Drug Education survey

DIS Diagnostic Interview Schedule

DSM Diagnostic Statistical Manual 
To appear in Current Opinion in Psychiatry, May 2007

\section{Introduction}

Public health concern about alcohol consumption and associated risk behaviours in young people is increasing, especially among college students who, in some countries, appear to be at particularly high risk. Indeed, the leading cause of injury and death among college students and young adults in the USA is reported to be binge drinking [1].

Studies from different parts of the world have shown that college students have a higher prevalence of alcohol drinking and alcohol use disorders, than non-college youth [2-4]. This could be attributed to the well established developmental phase college students go through, in which they are away from home, family and longstanding friendships. Throughout their college years, students pass through a phase of vulnerability (intellectually, emotionally and socially), in a new environment characterised by considerable peer influence, and often, aggressive promotion of alcoholic beverages. In addition to the college setting being a unique environment to which a large proportion of young people are exposed en masse, nearly all of the world's future leaders, policy makers, and healthcare providers, will have passed through the college system as young people.

In North America, college student drinking has been studied extensively (e.g., [5-7]), the problem receiving frequent media attention, research funding, and intervention programming [8-10]. Several factors have been found to be associated with alcohol use, abuse and dependence, such as genetic factors, environmental factors, emotional and psychological instability, gender, sexual identity, cognitive factors, peer pressure, family history, and achievement $[4,11]$. Although the problem of alcohol use is evident in most countries of the world, there is a comparatively small amount of research from a few European countries $[12,13]$ and Australasia [14-16]. Until recently, little was known about the patterns of college 
student drinking in many parts of the world, most notably in the Arab region [4,17] where cultural and religious affiliations of students have theoretically an important impact on alcohol use: not only does the religion of Islam (most common in the Arab region) forbid the use of alcohol, but in addition, many Arab countries forbid alcohol use by law. Despite these norms and legal restrictions, studies have revealed the presence of problems related to alcohol use among college students in Arab countries, especially in males [4,17] such as the use of other substances, unsafe sex, low academic achievements, and conduct problems [4].

Intervention during the formative college years may present an opportunity to attenuate the risk of long-term drinking problems. Accordingly, this review has an international focus; it includes studies of prevalence, risk factors, and intervention from Africa, Asia, Australasia, Europe, and South America.

A Medline (PubMed) search was conducted using the keywords student, college or university, drinking or alcohol, and covering all published articles in 2005 and 2006. An initial list of 132 abstracts was reviewed, and 24 articles were identified and retrieved as relevant to this paper. This review mainly tackles the prevalence and gender differences of alcohol use in the past year across the different countries, students' knowledge and attitudes towards alcohol, risk factors, and treatment of alcohol use. The articles included in this review concern student populations in Africa $(n=2)$, Asia $(n=2)$, Australasia $(n=10)$, Europe $(n=5)$, and South America $(n=5)$. For the sake of completeness, we have included two studies from 2004 from two Arab countries. 
To appear in Current Opinion in Psychiatry, May 2007

\section{Prevalence and risk factors}

Several studies have looked at the prevalence of alcohol drinking and related problems, with only few studies looking at predictive and/or protective factors.

\subsection{Africa}

Three studies have been identified by our search in Africa, one from Egypt [18], and two from Nigeria $\left[19,20^{*}\right]$.

Alcohol use and related problems

Refaat [18] assessed awareness and practice of health risk behaviour among 687 Egyptian students (response rate 95\%, 59\% females, 25\% medicine, $7 \%$ informatics, $34.5 \%$ education, $33.9 \%$ agriculture) from Suez Canal University. Of the students, $14.4 \%$ had ever tried alcohol, and 4.1\% reported current drinking. Current use of alcohol (and drugs) was more common among students: $\geq 19$ years $(\mathrm{OR}=3.5, \mathrm{CI}: 1.6-7.9)$, males $(\mathrm{OR}=6.5, \mathrm{CI}: 2.7-16.6)$, those receiving a higher allowance: $>100$ Egyptian pounds/month $(\mathrm{OR}=6.2, \mathrm{CI}: 1.7-23.1)$, those who were working $(\mathrm{OR}=3.7, \mathrm{CI}: 1.7-8.1)$, and students studying agriculture $(\mathrm{OR}=2.4$, CI: 1.1-6.0). About half (55.6\%) of the students had moderate knowledge of the dangers of using alcohol (or other substances), and the main source of information was friends $(46.7 \%)$, followed by media (43.3\%).

\section{Methodology}

Two other studies were identified from Africa, both from Nigeria [19,20*]. In the first study, Adewuya et al [19] investigated the screening properties of the 10-item AUDIT in a sample of 810 students from Obami Awolowo university. All students who scored at least $4(n=186)$ and $10 \%(n=62)$ of those who scored less than 4 on the AUDIT were given the CIDI (total $\mathrm{n}=248$ ). Alcohol related problems, according to clinical diagnoses and ICD-10, were present in 107 students ( $\mathrm{n}=76$ hazardous drinking, $\mathrm{n}=25$ harmful drinking, $\mathrm{n}=6$ alcohol dependence). 
The results on the AUDIT were highly correlated with results from the CIDI ( $\mathrm{r}=0.78$, $\mathrm{p}<0.001$ ), and using ROC analysis, cut-offs of 5 (sensitivity 0.935 , specificity 0.915 ), 7 (sensitivity 0.900 , specificity 0.862 ), and 9 (sensitivity 1.000 , specificity 0.941 ) on the AUDIT were reported by the authors to be appropriate in detecting hazardous drinking, harmful use, and dependence respectively.

\section{Alcohol use and anxiety}

In a second study, Adewuya et al [20*] evaluated the relation between alcohol use and selfrated anxiety symptoms among 86 university male students (50\% males), aged 20-30 years. Various categories of alcohol use were measured by the CIDI and ICD-10 criteria (abstainers, moderate drinkers, hazardous use, harmful use students, and dependence) and anxiety level was measured by Zung's SRAS. Overall there was an increase in anxiety levels with increase in alcohol use. Females showed a linear trend in patterns of alcohol use and anxiety, whereas there was a J-shaped trend among males.

\subsection{Asia}

As in Africa, three studies were reviewed from Asia: Hong Kong [21*], Turkey [22**] and from the Arab world, Lebanon [23**].

\section{Alcohol use and related problems}

In a study of first year Hong Kong university students during routine health screening $(n=2630)$, Griffiths and colleagues [21*] found very low rates of binge drinking: $7 \%$ reported having five or more drinks in an occasion in the preceding month, while $0.8 \%$ reported alcohol-related problems. 
To explore the relation between socioeconomic status (SES) and risk behaviours among young people, Oksuz and Malhan [22**], administered a health risk behaviour questionnaire to a stratified sample of 640 Turkish university students (48.9\% males, 51.1\% females). Alcohol use did not differ by study year (preparatory to $4^{\text {th }}$ year) and varied between $70.5 \%$ (preparatory) and $81.8 \%$ ( $2^{\text {nd }}$ year $)$. Alcohol use was predicted by being male $(\mathrm{OR}=1.91$, CI:1.29-2.85), and fathers' university education (OR=1.94, CI:1.21-3.12); whereas mothers' university education was protective $(\mathrm{OR}=0.47, \mathrm{CI}$ : $0.26-0.86)$. Heavier alcohol use was related to high SES, living with the family, and having parents with at least high school education.

From the Arab world, there were no published data in the past year, consequently, the authors reviewed relevant articles published in 2004. Only two articles were identified: one from Lebanon [23**] and a second from Egypt [18] reviewed above under Africa.

Before the 1990s there were no data on the prevalence of alcohol use, patterns, and covariates among university students in Lebanon; consequently Karam and colleagues [23**] conducted a study to gather comprehensive data on alcohol use as part of a series of prospective studies carried out each decade. The first study included two phases: Phase I was immediately after the end of the Lebanese wars (year 1991, n=1851) and Phase II (year 1999, n=1837) a decade later. Samples for both phases were selected from two major private universities in Lebanon. The first university (A) follows the American system and is situated in the West side of the Capital), while the second (F) follows the French system and is located in the East side of the capital Beirut. Students were given self-completed questionnaires based on the DIS-III (DSM-III) in Phase I, and on DIS-IV (DSM-IV) in Phase II. Both samples included similar gender distributions (Phase I: 51.5\% males, Phase II: 47.4\% males), mean ages (Phase 
I: 20.51, Phase II: 20.18), and religious distributions (Phase I: $64.1 \%$ Christians, 31.3\% Moslems, and 4.5\% Druze; Phase II: 57.6\% Christians, 37.5\% Moslems, and 4.9\% Druze). Lifetime alcohol use increased from the first to the second phase (from $49.2 \%$ to $70.8 \%$ ), abuse from $2.8 \%$ to $9.1 \%$, and dependence from $2.9 \%$ to $5.3 \%$. This increasing trend was present for all groups studied, by gender, age, religion (except for Moslems who practice their religion), each university, and the major field of study. The mean age of onset for drinking assessed in Phase II was 16.12 years $(\mathrm{sd}=2.69)$, being earlier in males than females and Christians than Moslems or Druze. The mean age of intoxication was similar between both phases (Phase I: $16.97 \pm 2.54$ years, Phase II: $17.04 \pm 2.41$ years). Alcohol related problems such as drunkenness before age 15 years, traffic accidents, legal problems, physical fights, and seeking consultation, increased from Phase I to Phase II, though experience of health related problems did not. Belief in God and practice of faith were protective in both phases against alcohol use, abuse, and dependence. A higher frequency of arguing daily with parents (over past 12 months), physical fights, and shop lifting were associated with a higher prevalence of alcohol use. The presence of a least one family member or a friend with excessive alcohol use was associated with more alcohol use among the students. Factors protective against alcohol use included: parents' strictness towards dress code and curfew, and parents' or friends' negative attitudes toward drinking $\geq 5$ drinks per week.

\subsection{Australasia}

Several studies have been published from Australia and New Zealand on alcohol use and alcohol related problems $[3 * *, 24 *-29]$.

Alcohol use and related problems

Two studies examined drink-driving in college populations. The first, in an Australian group of 275 psychology students (206 females) [24*], showed that $14 \%$ (12\% of females, $19 \%$ of 
males) reported driving in the preceding month after having more alcohol than was recommended for their sex and license category. Sixteen percent had been the passenger of a driver who they thought was over the legal blood alcohol limit $(0.05 \mathrm{~g} \%$ for persons on a full license, $0.02 \mathrm{~g} \%$ for those on a provisional license).

A similar question was posed to a random sample of 1,564 students at a New Zealand university $\left[25^{*}\right]$, of whom $63 \%$ met criteria for hazardous drinking (score $\geq 8$ on the AUDIT). Six percent ( $3 \%$ of females, $8 \%$ of males) reported that "they had driven after having had perhaps too much to drink" in the past four weeks, while 9\% said they had been the passenger of a drink-driver ( $7 \%$ of females, $11 \%$ of males). It is important to note that the legal blood alcohol limit for driving is higher in New Zealand $(0.08 \mathrm{~g} \%$ for drivers 20 years and over and $0.03 \mathrm{~g} \%$ for those under 20 years of age) than in Australia $(0.05 \%$ for fully licensed drivers, $0 \%$ to $0.02 \%$ for those with provisional licenses). The primary aim of this study was to determine the accuracy of students' estimates of how much they could drink and remain under the legal limit. Notably, $94 \%$ of students either correctly estimated or under-estimated the amount they could drink and remain under the legal limit, suggesting that the propensity to drink-driving is not due to lack of knowledge of the law.

There is growing interest in the USA in the possible role of class scheduling and drinking levels, there being a decreasing tendency, in recent years, for colleges to have classes on Friday, which has the unintended effect of increasing the length of the weekend and therefore opportunities for heavy drinking. Longitudinal survey data were collected from 866 students from residential halls at a New Zealand university, in semesters one and two [26**]. Around half ( $52 \%$ of males, $46 \%$ of females) drank $\geq 70 \mathrm{~g}$ or $\geq 50 \mathrm{~g}$ ethanol respectively for males and females, in a single episode in the preceding four weeks. Regression analyses were conducted 
to examine the associations between scheduling a Friday class in the second semester, alcohol use on different weeknights, and levels of alcohol use and heavy drinking in the past month. Students who did not schedule a Friday class in the second semester were more likely to report that their biggest drinking occasion was on Thursday compared to students who did schedule a Friday class. Scheduling a Friday class was inversely related to the frequency of past-month heavy drinking in the second semester among students who reported heavy drinking at least once per month at the beginning of the first semester. No statistically significant relationships were observed between scheduling a Friday class in the second semester and frequency or quantity of past-month alcohol use. The authors concluded that scheduling at least one Friday class may reduce the frequency of heavy alcohol use among college students, especially in those with a history of occasional or frequent heavy drinking.

Data from a survey of a random sample of 1,564 students at a New Zealand university (82\% response) were used to estimate the blood alcohol concentration (EBAC) resulting from each of 2,231 drinking episodes reported by the sample in the preceding seven days [27**]. EBACs of $>0.08 \mathrm{~g} \%$ were exceeded by $37 \%$ of women and $39 \%$ of men, and teenage females had higher EBACs than teenage males. Intoxication $(>0.08 \mathrm{~g} \%)$ was positively associated with lower age, European or Maori ethnicity relative to Asian, Pacific, or other ethnicities, and with residential halls relative to other living arrangements. Faculty of study was inconsistently related to intoxication.

Using AUDIT score data from the same survey, the researchers [3**] compared risk levels of 17-24 year-old students $(n=1,424)$ with those of the general population of the same age $(n=1,406)$ from a national household survey. The prevalence of hazardous drinking (score $\geq 8$ ) was almost twice as high in the students (65\% versus $36 \%)$, and harmful drinking (score 
$\geq 15)$ was three times as prevalent ( $31 \%$ versus $9 \%)$. This mirrors a recent US study comparing 18-29 year-olds in the general population with college students, which showed that monthly heavy drinking ( $5+$ drinks per occasion for men, $4+$ for women) was significantly more common in college students than in the general population $(24 \%$ versus $20 \%)$. A diagnosis of alcohol dependence was also significantly more common among college students than among their non-student peers (15\% versus $12 \%)$ [2].

\section{Knowledge of alcohol and perception of harm}

In a longitudinal study, Cape and colleagues assessed New Zealand medical students' knowledge of, attitudes toward, and use of, alcohol and drugs [28**]. At baseline (in $2^{\text {nd }}$ year), only $18 \%$ of the sample reported drinking more than once per week, and this remained fairly constant through to $6^{\text {th }}$ year. At baseline, $20 \%$ reported drinking six or more standard drinks ( $\geq 60 \mathrm{~g}$ ethanol) per occasion, and this prevalence decreased to $15 \%$ over the course of training, although it should be noted that attrition was high: of the 280 students enrolled in the study at $2^{\text {nd }}$ year, only $112(40 \%)$ participated in $6^{\text {th }}$ year.

Hasking and colleagues [29] examined drinking levels and knowledge of alcohol content in standard drinks and popular alcoholic beverages, and perceptions of risky drinking levels, in a convenience sample of 371 students (204 females) at an Australian university. The sample reported a mean drinking frequency of once per week, and approximately five drinks $(50 \mathrm{~g}$ ethanol) per occasion. Respondents generally over-estimated the amount of alcohol contained in a standard drink (mean estimate: $18.3 \mathrm{~g}$, actual amount: $10 \mathrm{~g}$ ), and the Australian government's thresholds for high risk drinking. 
To appear in Current Opinion in Psychiatry, May 2007

\subsection{Europe}

Only three European countries, Sweden [30**], Germany [31*], and Ireland [32**] have published on this topic from 2005 to 2006 .

\section{Alcohol use and related problems}

Bendsten and colleagues [30**] examined drinking levels and the feasibility of providing electronic screening and brief intervention (e-SBI) in a survey of 1,585 students (742 females, 843 males) at a Swedish university (response 44\%). Heavy episodic drinking ( $>48 \mathrm{~g} / 60 \mathrm{~g}$ ethanol for females/males), was reported by $51 \%$ of females and $71 \%$ of males at least monthly or more often. Forty percent of females and $56 \%$ of males said they experienced intoxication at least weekly, and blackouts were reported by $20 \%$ of females and $50 \%$ of males at least once in the preceding three months. The majority of students found the e-SBI program's feedback and advice easy to understand, and $25 \%$ (30\% of females, $20 \%$ of males) said they found the advice beneficial.

Keller and colleagues [31*] assessed the prevalence of binge drinking in 252 (response rate $74 \%$ ) first-year German medical students. For the two weeks preceding the survey, $24 \%$ ( $20 \%$ of females, $30 \%$ of males) reported one binge ( $\geq 56 \mathrm{~g}$ ethanol for women, $\geq 70 \mathrm{~g}$ ethanol for men) and a further $28 \%$ (24\% of females, $35 \%$ of males) reported two or more binge episodes. Frequent binge drinkers had a higher prevalence of smoking and other drug use. As in several studies from other countries (e.g. $[33,34]$ ), students over-estimated the drinking levels of their classmates.

Medical students are commonly considered an important subgroup of college students given their future important roles as medical practitioners in the identification and treatment of alcohol use disorders. In a series of cross-sectional, anonymous surveys of medical students 
in Ireland, conducted in 1973, 1990, and 2002, Boland and colleagues [32**] found significant increases in the overall prevalence of drinking. From 1990 to 2002, there were also increases in weekly volume consumed: from 14.3 units (8-10g ethanol per unit) to 19.4 units for males; and 6.0 to 9.5 units for females. In the same period, the proportion of students who were positive on the CAGE increased significantly: from $41 \%$ to $61 \%$ for males, and $28 \%$ to $47 \%$ for females. The proportion of students drinking above recommended limits increased by around $50 \%$ for males $(23 \%$ to $33 \%)$ and over $100 \%$ for females $(10 \%$ to $22 \%)$.

\subsection{South America}

From South America, three studies were conducted in Brazil [35*-37] to asses the prevalence of alcohol (and drug) use and related parameters among medical students, the patterns of alcohol (and drug) use among undergraduate students, and alcohol (and drug) use and risk behaviours among university students. Additionally, a fourth study from Brazil [38], looked only at the knowledge and attitudes of undergraduate nursing students towards alcohol (and other substances) misuse and education. One study from Ecuador assessed the use of psychoactive drugs (including alcohol) and risk behaviours among university students [39*].

\section{Alcohol use and related problems}

Stempliuk et al $\left[35^{*}\right]$ compared the attitudes and patterns of alcohol and drug use among undergraduate students at Sao Paulo University (Brazil) in $1996(\mathrm{n}=2543)$ and 2001 $(\mathrm{n}=2841)$. Both samples, drawn at different times using similar methods, were similar in areas of study, class scheduling and gender distribution. The authors analysed students' approval of alcohol and psychoactive drug use, and found an increased approval of experimentation and use of psychoactive drugs, and an overall decrease in approval and use of alcohol from 
To appear in Current Opinion in Psychiatry, May 2007

1996 to 2001 . Lifetime use of alcohol increased from $88.5 \%$ to $91.9 \%(p=0.006)$ from 1996 to 2001 .

Using the YRBS, Pillon and colleagues [36*] studied the use of drugs among 200 freshman or first year university students (50\% females) in Brazil, finding that $86.5 \%$ of the sample had ever had at least one drink of alcohol (one beer can, one wine glass, $40 \mathrm{ml}$ cachaca). In the preceding 30 days, $75 \%$ reported having at least one drink of alcohol (100\% of males). As others have shown [4], alcohol was typically first used at an earlier age than tobacco and other drugs, well before the college years (mean age 13, sd=2 years). Eighteen percent of males and $7 \%$ of the females reported driving at least once while intoxicated. Drunkenness and intoxication were more common among males; $33 \%$ of males reported being drunk on at least 7 occasions at any time in their life, vs. $13.5 \%$ of females reporting being drunk once or twice. When asked about drinking alcohol while attending university in the past month, $10.5 \%$ had at least one dose of alcohol. Of the male students, $10 \%$ used alcohol or drugs before engaging in sexual activity, and $17.5 \%$ had more than one sexual partner. Only $33 \%$ of the students used condoms, and $65 \%$ of these were males. Problems associated with alcohol use included passing out or forgetting what happened after alcohol consumption (28\%). When asked about their perception of how harmful the occasional use of alcohol is, $15 \%$ of males and $20 \%$ of females thought this was harmful. Both genders reported easy access to alcoholic drinks. Reasons reported for using alcohol included having fun (74\%), escaping problems (59\%), and peer influence (54\%).

Passos et al [37] estimated the prevalence of drug use and related characteristics among medical students in four public universities in Rio de Janeiro (Brazil). Alcohol was the most frequently used substance: out of the 1054 participants, 1005 (96.4\%) reported ever drinking, 
and 588 (58.8\%) doing so in the last 30 days. Using the CAGE, 19.8\% students were identified as having alcohol abusing behaviour. Alcohol abuse was predicted by being a male $(\mathrm{OR}=2.34, \mathrm{CI}: 1.64-3.16)$, and high family income $(\mathrm{OR}=1.28, \mathrm{CI}: 1.01-1.62)$.

In Ecuador, Chavez and colleagues [39*] assessed the use of alcohol (and other substances) and risk behaviours in a sample of 751 first year college students ( $56 \%$ females) at University of Guayaquil, using the YRBS. Results showed that most students used alcohol experimentally in the preceding six months, with men experimenting more than women $(\mathrm{p}<0.005)$, and $83 \%$ of the students reported lifetime use of alcohol inside and outside university. Among lifetime drinkers, 39\% were reported to be abusive, resulting in drunkenness, $21.4 \%$ enjoyed having 1 to 2 drinks, $14 \%$ drank to get "a bit high", $23.5 \%$ drove after drinking, out of which $17 \%$ had accidents after drinking. Out of those who engaged in sexual activities, 55.3\% drank alcohol prior to it. Being the first research conducted in a college sample in Ecuador, this study served to highlight the importance of developing prevention programs for substance use and treating this as a priority.

\section{Knowledge of alcohol and perception of harm}

Rassool and colleagues [38] examined knowledge and attitudes toward substance misusers among 227 fourth year undergraduate nursing students in Brazil (87.2\% females, $73.5 \% 20$ 25 years), using the revised 22-item NEADA scale. When assessing education and knowledge, the majority of students $(83.7 \%)$ reported that the basic education was inadequate, and $75.7 \%$ thought it is needed to take an alcohol and drug history from patients. When asked about nursing interventions, $85.4 \%$ thought that nurses could help in changing drinking habits, and $80.6 \%$ thought that nurses have the responsibility to intervene when patients are using drugs. Questions on attitudes and values revealed that $87.2 \%$ of nurses felt 
it is not an invasion of privacy to ask patients about substance use, and $89.3 \%$ agreed that alcoholism is not a sign of moral weakness. The authors conclude that nurses do have a positive attitude towards alcoholic patients and that alcohol education needs to be added to their curriculum.

Students' alcohol use ought to be considered in the context of alcohol consumption in the general population of each country [40]. For example, alcohol consumption and related health risks were uncommon in Turkey, where per capita consumption is approximately 1.5 liters absolute alcohol per year, compared with far higher consumption in many countries, including Australia (9.2 liters), Germany (12.9 liters), Ireland (13.7 liters), the Netherlands (9.7 liters), New Zealand (9.8 liters), Nigeria (10.0 liters), and the USA (8.5 liters). Other countries reviewed in this paper have more moderate per capita consumption: Brazil (5.3 liters), Ecuador (2.0 liters), Egypt (0.2 liters), Lebanon (4.1 liters), and Sweden (6.7 liters).

\section{Intervention}

In contrast to the USA, where the drinking age is 21 , most other developed countries legally permit alcohol consumption at any age, having a minimum purchase age of 18 (UK, many European countries, some Canadian provinces, Australia and New Zealand), or 19 (some Canadian provinces). This creates a context for college alcohol consumption which is somewhat different to that of the USA, where campus authorities can focus to a large extent on the policing of underage drinking. The intervention studies identified for this review include clinical trials of three types of individually focused interventions aimed at reducing demand for alcohol. 
To appear in Current Opinion in Psychiatry, May 2007

\subsection{Australasia}

Three studies from Australasia examined the effects of alcohol intervention [41**,42*,43**]. Electronic screen and brief intervention

As part of a large randomised controlled trial of electronic screen and brief intervention (eSBI) in the primary care setting at a New Zealand university, 1,010 patients ( $90 \%$ of those invited) completed web-based screening while in the waiting room [41**]. Sixty percent of women and $73 \%$ of men screened positive for hazardous drinking (score of $\geq 8$ on the AUDIT). Only 4\% of persons who screened positive declined to be contacted for follow-up. The findings are consistent with those of Bendtsen and colleagues' Swedish study [30**], and research from the USA [44], showing that many drinkers find the web-based approach appealing and easy to use.

Two randomised controlled trials examined the efficacy of e-SBI in the primary care setting at a New Zealand university. In the first [42*], patients of the student health service were invited to complete a computerised health screening program in the reception area as they waited to be seen by a doctor. Of 277 patients invited to participate, 218 consented and were randomly allocated to one of three groups: no assessment control, computerised assessment only, and computerised assessment plus personalised feedback. Assessment included measures of physical activity, diet, alcohol use and smoking. Intervention involved the provision of criterion and normative feedback and health information. Web-based follow-up assessments were completed by 181 participants six weeks later. Hazardous drinking prevalence did not differ significantly between groups at follow-up. This may have been due to the large proportion $(25 \%)$ of non-hazardous drinkers in the trial, which may have diluted intervention effects. 
In a second RCT, which built on a pilot RCT showing benefits of 15 minutes of e-SBI up to six months later [45], Kypri and colleagues [43**] explored the concept that assessment of students' drinking risk status without subsequent intervention might have beneficial effects. In the same student health service, 975 patients (17-29 years) completed a web-based AUDIT questionnaire. Of 599 who scored $\geq 8$ (mean 15.0, SD 5.2), 576 consented to follow-up and were included in a four-arm trial, of whom 293 (153 women) were assigned to either a group which received an information leaflet at baseline, or a group which received the information leaflet and 10 min of web-based assessment 4 weeks later. A year after baseline, relative to the leaflet only group, those who received web-based assessment reported significantly lower overall consumption $(-18 \%)$, fewer heavy drinking episodes (-34\%), fewer problems $(-19 \%)$, and lower AUDIT scores (-1.6 points).

\subsection{Europe}

In Europe, studies on alcohol intervention were reported from the Netherlands [46**] and Sweden $\left[47^{* *}\right]$.

\section{Expectancy challenge}

The notion that heavy drinkers have expectations about the effects of alcohol which are unduly positive, has attracted considerable research interest. In the expectancy challenge paradigm, questionnaires are used to assess alcohol expectancies, and the behaviour of drinkers is then observed after they consume non-alcoholic beverages made to look, smell, and taste like alcohol. A study identified in this review took the novel approach of assessing implicit (as well as the commonly measured explicit) expectancies, thereby reducing the likelihood of social desirability in the initial reporting of expectancies and post test drinking, biasing the results. Ninety-two heavy drinkers were recruited at a Dutch university and randomly assigned to expectancy challenge or a control condition [46**]. Alcohol 
consumption and implicit alcohol-related cognitions were assessed at baseline and for the month following the intervention. Three to four weeks after baseline, there were some reductions in drinking and explicit expectancies in the intervention group relative to controls. The results were less compelling with regard to implicit expectancies.

\section{Students who have parents with alcohol problems}

A Swedish study examined the efficacy of an alcohol intervention program, a coping program, and a combination of the two, in a 3-arm RCT with 82 university student drinkers (56 women, 22 men, mean age of 25) who had grown up in an environment in which, according to the participant, one or both parents had a drinking problem [47**]. The alcohol intervention used the Brief Alcohol Screening for College Students manual [48], based on motivational interviewing with psychoeducation [49]. The coping intervention was based on a manual developed by the authors, and included reflection on the participant's familial experience, and instruction in coping techniques in a variety of life domains. The combined intervention included elements of both programs. All the programs involved two 2-hour sessions administered one month apart. The study had high participant retention: $100 \%$ completed the intervention, and 95\% completed 12-month follow-up assessments. Relative to the coping intervention, those who received the alcohol intervention reported lower alcohol consumption at 12 months (standardised difference of $-0.27,95 \% \mathrm{CI}-0.53$ to -0.03 ).

\section{Conclusions}

This review examined a heterogeneous set of recent studies from Africa, Asia (including the Arab world), Australasia, Europe, and South America, which have shown repeatedly that college students are a high risk group for heavy drinking and alcohol-related problems. The majority of studies reported results from convenience rather than representative college 
samples, limiting their generalizability and making international comparisons difficult. Consequently, there is a clear lack of representative data on college alcohol use and related problems in these regions. Lastly, any research on substance use could be affected by the validity of the answers obtained in a field were desirability might affect transparency, thus numbers being obtained are probably an under representation of alcohol use and abuse. Still using what has been published for an initial assessment of alcohol use patterns among students, permits indicative comparisons with the large research literature on college drinking in North America.

Relative to North America, problematic alcohol use (hazardous drinking, heavy drinking, abuse, and dependence) has a similar prevalence in Australasia, Europe, and South America, and a lower prevalence in Africa and Asia. Similar risk and protective factors were identified, such as male gender, higher SES, and higher family education, as well as family and/or peer excessive use if alcohol. Karam et al [23**] found in Lebanon, protective factors, such as belief in God, practice of faith, and family or peer negative attitudes towards excessive drinking were important. In three repeated cross-sectional studies, in Lebanon $\left[23^{* *}\right]$, Ireland $\left[32^{* *}\right]$, and Brazil [35*], the prevalence of drinking and/or alcohol consumption was found to have increased through the 1990s. Possible environmental risk factors were identified, included not having classes on Fridays [26**], and living in a residential hall $\left[4,27^{* *}\right]$. Alcohol use was positively associated with anxiety levels, smoking, other substance use, and drink-driving. Students in Australasia had relatively poor knowledge of standard drink alcohol content, risky drinking levels, and permissible consumption levels for driving [24*, 25*, 29]. 
To appear in Current Opinion in Psychiatry, May 2007

Provision of web-based screening and brief intervention was shown to be feasible in Sweden and New Zealand, acceptable to students, and effective in reducing hazardous drinking for 612 months $\left[30^{* *}, 41^{* *}\right]$. For students whose parents had/have alcohol problems, two 2 -h sessions of motivational intervention and psychoeducation were effective in reducing consumption at 12 months [47**].

In many countries, particularly in Europe, Australasia, and South America, college student drinking is problematic, to an extent similar to that reported in North America. There is evidence from some countries of increasing consumption and binge drinking. Similar risk factors were identified, and there is some evidence of effective individually focused intervention. Further research is needed on environmental and policy influences on drinking behaviour which incorporate the risk and protective factors reviewed above in the unique environment of college life. 
To appear in Current Opinion in Psychiatry, May 2007

\section{References}

1. Hingson RW, Heeren T, Zakocs RC, Kopstein A, Wechsler H. Magnitude of alcohol-related mortality and morbidity among US college students ages 18-24. Journal of Studies on Alcohol 2002;63(2):136-144.

2. Dawson DA, Grant BF, Stinson FS, Chou PS. Another look at heavy episodic drinking and alcohol use disorders among college and non-college youth. Journal of Studies on Alcohol 2004;65(4):477-489.

3. Kypri K, Cronin M, Wright CS. Do university students drink more hazardously than their non-student peers? Addiction 2005;100(6):713-714.

** A New Zealand comparison of survey data from university students with similar aged youth in a national household survey showing much higher prevalence of hazardous and harmful consumption in students.

4. Karam EG, Ghandour L, Maalouf W, Yamout K. Substance Use and Misuse in Lebanon: The Lebanon Rapid Situation Assessment and Response Study. UNODC Report 2003.

5. Johnston LD, O'Malley PM, Bachman JG. Smoking, drinking, and illicit drug use among American secondary school students, college students, and young adults, 1975-1991.: National Institute on Drug Abuse, U.S. Department of Health and Human Services.; 1992.

6. Wechsler H, Davenport A, Dowdall G, Moeykens B, Castillo S. Health and behavioral consequences of binge drinking in college. A national survey of students at 140 campuses. Journal of the American Medical Association 1994;272(21):16721677.

7. Wechsler H, Dowdall GW, Davenport A, Castillo S. Correlates of college student binge drinking. American Journal of Public Health 1995;85(7):921-926. 
To appear in Current Opinion in Psychiatry, May 2007

8. National Institute on Alcohol Abuse and Alcoholism. Changing the culture of campus drinking. Alcohol Alert 2002;58:1-4.

9. National Institute on Alcohol Abuse and Alcoholism: Task Force on College Drinking. How to reduce high-risk college drinking: use proven strategies, fill research gaps.: National Institute of Health.; 2002 April.

10. National Institute on Alcohol Abuse and Alcoholism: Task Force on College Drinking. High-risk drinking in college: What we need to learn: National Institute of Health.; 2002 April.

11. Boyd CJ, Mccabe SE, Morales M. College students' alcohol use: a critical review. Annu Rev Nurs Res 2005;23:179-211

12. Nystrom M, Perasalo J, Salaspuro M. Screening for heavy drinking and alcoholrelated problems in young university students: the CAGE, the Mm-MAST and the trauma score questionnaires. Journal of Studies on Alcohol 1993;54(5):528-533.

13. Webb E, Ashton CH, Kelly P, Kamali F. Alcohol and drug use in UK university students. Lancet 1996;348(9032):922-925.

14. Roche AM, Watt K. Drinking and university students: From celebration to inebriation. Drug and Alcohol Review 1999;18:389-399.

15. Wilks J. Drinking patterns of Australian tertiary youth. Australian Drug and Alcohol Review 1989;8:55-68.

16. Kypri K, Langley JD, McGee R, Saunders JB, Williams S. High prevalence, persistent hazardous drinking in New Zealand tertiary students. Alcohol and Alcoholism 2002;37(5):457-464.

17. Suleiman RA, Shareef M, Kharabsheh S, Abu Danoon M. Substance Use among University and College Students in Jordan. The Arab Journal of Psychiatry 2003; 14 (2): $94-105$ 
To appear in Current Opinion in Psychiatry, May 2007

18. Reefat A. Practice and awareness of health risk behavior among Egyptian university students. Eastern Mediterranean Health Journal 2004; 10:72-81.

19. Adewuya AO. Validation of The Alcohol Use Disorders Identification Test (Audit) As a Screening Tool For Alcohol-Related Problems Among Nigerian University Students. Alcohol \& Alcoholism 2005; 40(6):575-577.

20. Adewuya AO, Ola B, Olutayo, A. Gender Differences in the Relationship Between Alcohol Use and Anxiety Symptoms Among Nigerian College Students. Drug and Alcohol Dependence 2006; 85(3):255-257

* An interesting study from Nigeria focusing on the use of alcohol and the possible links to anxiety in students.

21. Griffiths S, Lau JT, Chow JK, Lee SS, Kan PY, Lee S. Alcohol use among entrants to a Hong Kong University. Alcohol 2006;41(5):560-565.

* A survey of first year students showing a low prevalence of heavy episodic drinking.

22. Oksuz E, Malhan S. Socioeconomic Factors and Health Risk Behaviors among University Students in Turkey: Questionnaire Study. Croatian medical journal 2005;46(1):66-73.

** This is an important study on risk behaviors among college students from Turkey, a country with a predominant Moslem population, yet with at least three generations living in an atmosphere of the more liberal European cultures.

23. Karam EG, Maalouf W, Ghandour L .Alcohol Use among University Students in Lebanon: Prevalence, Trends and Covariates The IDRAC University Substance Use Monitoring Study (1991 and 1999). Drug and Alcohol Dependence 2004; 76: 273286.

** This is a large study that assesses alcohol use, abuse, and dependence in colleges, the only one so far from an Arab country with both Christianity and Islam (and their different 
attitudes towards alcohol use ) and which covers predictive and protective in two phases a decade apart.

24. Davey JD, Davey T, Obst PL. Drug and drink driving by university students: an exploration of the influence of attitudes. Traffic Inj Prev 2005;6(1):44-52.

* An Australian survey-based study reporting prevalence and attitudes associated with drinkdriving in a convenience sample.

25. Kypri K, Stephenson SCR. Drink-driving and perceptions of legally permissible alcohol use. Traffic Injury Prevention 2005;65(3):219-224.

* A New Zealand survey of a random sample reporting prevalence of drink-driving and students' estimates of how much they could drink and remain below legal limits.

26. Paschall MJ, Kypri K, Saltz RF. Friday class and heavy alcohol use in a sample of New Zealand college students. J Stud Alcohol 2006;67(5):764-769.

** A New Zealand cohort study examining the hypothesis that having Friday classes reduces heavy drinking.

27. Kypri K, Stephenson SCR, Langley J. Episode-centered analysis of drinking to intoxication in university students. Alcohol \& Alcoholism 2005;40(5):447-452. ** A New Zealand survey of a random sample in which BACs were estimated for each drinking episode in the preceding seven days.

28. Cape G, Hannah A, Sellman D. A longitudinal evaluation of medical student knowledge, skills and attitudes to alcohol and drugs. Addiction 2006;101(6):841-849. ** A New Zealand cohort study examining consumption and attitudes toward alcohol in students from four medical schools in $2^{\text {nd }}, 4^{\text {th }}$, and $6^{\text {th }}$ years.

29. Hasking P, Shortell C, Machalek M. University students' knowledge of alcoholic drinks and their perception of alcohol-related harm. J Drug Educ 2005;35 (2):95-109. 
30. Bendtsen P, Johansson K, Akerlind I. Feasibility of an email-based electronic screening and brief intervention (e-SBI) to college students in Sweden. Addict Behav 2006;31 (5):777-787.

** A Swedish survey study in which uptake and acceptability were measured in students invited to receive on-line screening and motivational feedback.

31. Keller S, Maddock JE, Laforge RG, Velicer WF, Basler HD. Binge drinking and health behavior in medical students. Addict Behav 2006.

* A German survey study examining binge drinking prevalence and perceived norms in firstyear medical students.

32. Boland M, Fitzpatrick P, Scallan E, Daly L, Herity B, Horgan J, et al. Trends in medical student use of tobacco, alcohol and drugs in an Irish university, 1973-2002. Drug Alcohol Depend 2006;85(2):123-128.

** An Irish survey study examining alcohol consumption and problems among medical students, at three points over 29 years.

33. Baer JS, Stacy A, Larimer M. Biases in the perception of drinking norms among college students. Journal of Studies on Alcohol 1991;52(6):580-586.

34. Kypri K, Langley JD. Perceived norms and their relation to university student drinking. Journal of Studies on Alcohol 2003;64(6):829-834.

35. Stempliuk V, Barroso LP, Andrade G, Nicastri S, Malbergier A. Comparative Study of Drug Use Among Undergraduate Students at the University of São Paulo campus in 1996 and 2001. Revista Brasileira de Psiquiatria 2005;27(3):185-93.

* This study covers not only alcohol use but also that of other substances in a college setting in Brazil reinforcing a recurring call from other international studies, to devote special attention to the initiation of prevention and treatment programs. 
To appear in Current Opinion in Psychiatry, May 2007

36. Pillon S, O'Brein B, Chavez K. The Relationship Between Drugs Use and Risk Behaviors in Brazilian University Students. Revista latino-americana de enfermagem 2005; 13 (número especial):1169-1176

* A study from Brazil that tackles the serious problem of risky behaviors and their relation to substance abuse, in the college setting.

37. Passos S, Brasil P, Santos M, Aquino MT. Prevalence of Psychoactive Drug Use Among Medical Students in Rio de Janeiro. Social Psychiatry and Psychiatric Epidemiology 2006.

38. Rassool GH, Villar-Luis M, Carraro TE, Lopes G. Undergraduate Nursing Students' Perceptions of Substance Use and Misuse: a Brazilian Position. Journal of Psychiatric and Mental Health Nursing 2006;13:85-89.

39. Chavez K, O'Brien B, Pillon S. Drugs Use and Risk Behavior in a University Community. Revista latino-americana de enfermagem 2005; 13(número especial):1194-1200

* This study offers us a welcome source of data on the prevalence of alcohol and other drugs use and related risky behavior in the college setting in Ecuador

40. World Health organization. Global Status report on Alcohol 2004. Geneva: WHO; 2004. Available at http://www.who.int/ substance abuse/ publications/ global_status report_alcohol_2004alcconsumpt.pdf

41. Kypri K, Stephenson SCR, Langley JD, Cashell-Smith ML, Saunders JB, Russell D. Computerized screening for hazardous drinking in primary care. New Zealand Medical Journal 2005;118(1224):1-9.

** A New Zealand study examining uptake of web-based screening among patients of a student health service. 
To appear in Current Opinion in Psychiatry, May 2007

42. Kypri K, McAnally HM. Randomized controlled trial of a web-based primary care intervention for multiple health-risk behaviors. Preventive Medicine 2005;41(3); 761766.

* A New Zealand RCT of e-SBI for diet, physical activity, smoking, and hazardous drinking, in which student health service patients were randomised to assessment and motivational feedback, assessment alone, or no assessment.

43. Kypri K, Langley JD, Saunders JB, Cashell-Smith ML. Assessment may conceal therapeutic benefit: findings from a randomized controlled trial for hazardous drinking. Addiction 2006;102(1):62-70.

** A New Zealand RCT in which student health service patients were randomised to receive web-based assessment of their drinking versus an information leaflet, with web-based followup 6- and 12-months later.

44. Saitz R, Helmuth ED, Aromaa SE, Guard A, Belanger M, Rosenbloom DL. Webbased screening and brief intervention for the spectrum of alcohol problems. Prev Med 2004;39(5):969-975.

45. Kypri K, Saunders JB, Williams SM, McGee RO, Langley JD, Cashell-Smith ML, et al. Web-based screening and brief intervention for hazardous drinking: A doubleblind randomized controlled trial. Addiction 2004;99(11):1410-7.

46. Wiers RW, van de Luitgaarden J, van den Wildenberg E, Smulders FT. Challenging implicit and explicit alcohol-related cognitions in young heavy drinkers. Addiction 2005;100(6):806-819.

** A Dutch RCT examining the effects of expectancy challenge on drinking, explicit and implicit expectancies, 3-4 weeks later. 
To appear in Current Opinion in Psychiatry, May 2007

47. Hansson H, Rundberg J, Zetterlind U, Johnsson K, Berglund M. An intervention program for university students who have parents with alcohol problems: a randomized controlled trial. Alcohol and Alcoholism 2006;41(6):655-63.

** A Swedish 3-arm RCT comparing motivational interview/psycho-education versus a coping skills program, versus a combination both interventions.

48. Dimeff LA, Baer JS, Kivlahan DR, Marlatt GA. Brief Alcohol Screening and Intervention for College Students (BASICS): A harm reduction approach. New York, NY, USA: The Guilford Press; 1999.

49. Miller WR, Rollnick S. Motivational interviewing : preparing people to change addictive behavior. New York: Guilford Press; 1991. 